\title{
Proteins involved in the Vroman effect during exposure of human blood plasma to glass and polyethylene
}

\author{
P. Turbill*, T. Beugeling and A.A. Poot \\ University of Twente, Department of Chemical Technology, P.O. Box 217, 7500 AE Enschede, The Netherlands
}

\begin{abstract}
The amounts of fibrinogen adsorbed to glass from various human blood plasmas have been measured as a function of time. The plasmas were 11 single donor plasmas, pooled plasma, a single donor high molecular weight kininogen (HMWK)-deficient plasma and HMWK-deficient plasma, which had been reconstituted with HMWK. For adsorption times between $1 \mathrm{~min}$ and $1 \mathrm{~h}$ more fibrinogen adsorbed from HMWK-deficient plasma compared with the amounts of fibrinogen which adsorbed from the other plasmas. This result supports the conclusion of several authors that HMWK is involved in the displacement of fibrinogen, initially adsorbed from normal human plasma to glass. Glass surfaces, preexposed to solutions of plasma and subsequently exposed to $1: 1$ diluted plasma, gives rise to a relatively high adsorption of HMWK which is independent of the plasma concentration of the precoating solution. The results indicate that HMWK from 1:1 diluted plasma is involved in the displacement of proteins from glass surfaces which had been pre-exposed to solutions with a low plasma concentration. Experiments with polyethylene as a substrate reveal that high density lipoprotein (HDL) from 1:1 diluted plasma is involved in the displacement of proteins from polyethylene surfaces which had been pre-exposed to solutions with a low plasma concentration. Moreover, evidence is presented that substantial amounts of albumin and fibrinogen, adsorbed from 1:1000 diluted plasma to glass and polyethylene, are displaced from the surfaces of these materials by proteins from 1:1 diluted plasma different from HMWK and HDL. Copyright (C) 1996 Elsevier Science Limited
\end{abstract}

Keywords: Proteins, Vroman effect, polyethylene

Received 12 June 1995; accepted 20 August 1995

After contact of blood (or plasma) with an artificial surface, a rapid adsorption of plasma proteins onto the surface takes place. It is generally assumed that all further events, such as platelet adhesion and blood coagulation, are determined by the composition and structure of the initially adsorbed protein layer.

From in vitro and ex vivo experiments it has been realized that the adhesion of platelets is promoted when proteins such as fibrinogen, von Willebrand factor and fibronectin have been (pre)adsorbed to a material surface $e^{1,2}$. However, platelet adhesion is reduced when pre-adsorbed albumin or high density lipoprotein (HDL) is present on the surface ${ }^{1,3,4}$.

The degree of surface activation of blood coagulation (contact activation) is also dependent on the adsorbed protein layer, because the primary event of this process is the adsorption of clotting factor XII and a subsequent conformational change of this protein upon the material surface which results in an enzymatic activity against the plasma protein prekallikrein ${ }^{5}$. Prekallikrein circulates in plasma as a complex with

Correspondence to Dr T. Beugeling.

*Present address: South Australian Institute of Technology, Adelaide, S.A. 5000, Australia. high molecular weight kininogen (HMWK), which accelerates the enzymatic conversion of prekallikrein. As will be discussed here, HMWK and HDL are supposed to play a role in the so-called Vroman effect. Studies by Vroman and Adams ${ }^{6}$ and Vroman et al ${ }^{7,8}$ revealed that fibrinogen, initially adsorbed from human plasma onto hydrophilic glass-like surfaces, is no longer immunologically detectable after a few minutes of contact time. This 'conversion' of surface adsorbed fibrinogen was markedly delayed when HMWK-deficient plasma was used instead of normal plasma. When HMWK-deficient plasma was reconstituted with HMWK, fibrinogen was no longer detected on the surface.

Brash and ten Hove ${ }^{9}$ and Brash et al. ${ }^{10}$ studied fibrinogen adsorption from (diluted) plasma by adding ${ }^{125}$ I-fibrinogen as tracer protein to the plasma. Their results strongly indicate that 'conversion' of fibrinogen, adsorbed from plasma to glass, is owing to a displacement of this protein from the material surface with increasing contact time. Results of experiments, carried out by Elwing et al. ${ }^{11}$ and Poot et al. ${ }^{12}$, support the hypothesis that fibrinogen adsorbed from plasma to glass is displaced by HMWK. It has been suggested by Vroman (in Brash and ten Hove ${ }^{9}$ ) 
that by diluting plasma sufficiently the concentration of HMWK decreases to such a low value that adsorbed fibrinogen cannot be replaced anymore. This hypothesis is supported by the results of several authors who found that the adsorption of fibrinogen and several other proteins to various materials as a function of the plasma concentration shows a maximum at a plasma dilution of 1:100$1: 1000^{9,10,12,13}$.

Both this plasma dilution effect and the abovementioned displacement of fibrinogen are called the Vroman effect by Horbett ${ }^{14}$. As suggested by Brash ${ }^{15}$ the Vroman effect at the present moment more generally refers to the sequential displacement of proteins adsorbing from plasma (or a mixture of proteins in solution) to a material surface.

The HMWK-deficient plasma used in the adsorption experiments of Vroman et al. ${ }^{7}$, Brash et al. ${ }^{10}$, and Poot et al. ${ }^{12}$ was obtained from George King Biochemicals (Overland Park, KS, USA), while the experiments of Schmaier et al. ${ }^{8}$ were carried out with donated HMWK-deficient plasma as well as donated plasma which was deficient in both high and low molecular weight kininogen. All the deficient plasma mentioned above were single donor plasmas. In the experiments of Brash et al. ${ }^{10}$, Schmaier et $a .^{8}$ and Poot et al. ${ }^{12}$, fibrinogen adsorption from the deficient plasmas was compared with the adsorption of fibrinogen from pooled normal human plasma, while Vroman et $a l^{7}$ used samples of different single donor plasmas. The amount of adsorbed fibrinogen may, however, depend on the plasma composition. Slack and Horbett ${ }^{16}$, for instance, found that the adsorption of fibrinogen from solutions of baboon plasma to polyethylene varied markedly with plasma fibrinogen concentration. For this reason we measured the adsorption of fibrinogen to glass from 11 normal donor plasmas and pooled plasma as a function of time. The 11 donors did not belong to the group of 15 donors, who donated blood for the preparation of pooled plasma. In addition we measured fibrinogen adsorption from single donor HMWK-deficient plasma and the same plasma, which had been reconstituted with HMWK.

Several studies on the adsorption of proteins to hydrophobic polymeric surfaces revealed that the most abundant plasma proteins are adsorbed in much smaller quantities from plasma than from protein solutions $^{13,17,18}$. The results off Breemhaar et al.$^{13}$ and Poot et $a .^{12}$ indicate that the small amounts of fibrinogen (and other proteins) adsorbed from plasma to hydrophobic polymers like PVC, polystyrene and polyethylene are owing to a preferential adsorption of HDL.

Poot et al..$^{12}$ found that at a plasma concentration of $50 \%$, plateau values for the adsorption of both fibrinogen and HDL to polyethylene were reached in about $1 \mathrm{~min}$. Therefore they concluded that initially adsorbed fibrinogen is not displaced by HDL, but their results also revealed that HMWK is not involved in a displacement of fibrinogen which has been adsorbed to polyethylene. On the contrary, when polyethylene is exposed to 1:1 deluted normal plasma, the amount of initially adsorbed HMWK decreases with increasing contact time.
To investigate a possible displacement of plasma proteins, adsorbed to glass and polyethylene surfaces by respectively HMWK and HDL, these surfaces were first pre-exposed to solutions with different concentrations of plasma, resulting in adsorbed protein layers with different protein compositions. The precoated surfaces were subsequently exposed to 1:1 diluted plasma. Thereafter the amounts of HMWK in the newly formed protein layers on glass were compared with the amounts of this protein present on the precoated glass surfaces. In the case of polyethylene, the amounts of HDL in the newly formed protein layers were compared with the amounts of HDL present on the precoated polyethylene surfaces. Moreover, the amounts of albumin and fibrinogen adsorbed to glass and polyethylene from 1:1000 diluted plasma were compared with the amounts of these proteins adsorbed to the surfaces which were first exposed to 1:1000 diluted plasma and subsequently exposed to $1: 1$ diluted plasma.

\section{MATERIALS AND METHODS}

\section{Test device}

Protein adsorption from plasma solutions to the material surfaces was studied by means of a two step enzyme-immunoassay ${ }^{12,19}$. In this enzymeimmunoassay a 24 wells test device was used. This device allows the adsorption as well as the detection of proteins on polymer sheets or glass plates. The test surface area and the maximum content of each well are $0.9 \mathrm{~cm}^{2}$ and $800 \mu \mathrm{L}$ respectively. A detailed description of the test device has been given by Poot et al. $^{12}$.

\section{Material surfaces}

Glass plates were obtained from Corning, New York, USA (hard glass, type 7059, thickness $2 \mathrm{~mm}$ ). Polyethylene sheet (low density polyethylene, thickness $0.05 \mathrm{~mm}$ ) was obtained from TALAS, Zwolle, The Netherlands.

Glass plates were cleaned for $15 \mathrm{~h}$ in a mixture of fuming nitric acid $(10 \mathrm{~mL})$ and fuming hydrochloric acid ( $33 \mathrm{~mL}$ ) followed by extensive rinsing with double distilled water and ethanol (ethanol, absolut zur Analyse, Merck, Germany). The clean glass plates were dried in air.

Polyethylene sheets were cleaned ultrasonically for $15 \mathrm{~min}$ in a $1 \%(\mathrm{v} / \mathrm{v})$ detergent solution (RBS 25, Hicol, Rotterdam, The Netherlands), followed by extensive rinsing with double distilled water and ethanol (see above). Sheets were dried in air.

\section{Plasmas and HMW kininogen}

Pooled normal human plasma was obtained from 15 healthy male donors. From each donor $100 \mathrm{~mL}$ of venous blood was collected via a $1.5 \mathrm{~mm}$ needle and 'Silastic' Medical-Grade tubing (length $15 \mathrm{~cm}, 3 / 16$ in ID) into two polypropylene centrifuge tubes $(50 \mathrm{ml}$ each), containing anticoagulant. The anticoagulant was $130 \mathrm{mM}$ trisodium citrate and the anticoagulant to 
blood ratio was $1: 9(\mathrm{v} / \mathrm{v})$. The tubes were centrifuged for $15 \mathrm{~min}$ at $1570 \mathrm{~g}$ and the remaining plasmas were centrifuged for $15 \mathrm{~min}$ at $3000 \mathrm{~g}$. Thereafter, the plasmas were pooled in a polypropylene beaker of $1000 \mathrm{~mL}$ and the pooled plasma was transferred into polypropylene vessels of $2.2 \mathrm{~mL}$. Vessels with plasma were kept at $-30^{\circ} \mathrm{C}$. Just before us, plasma was thawed in a water bath of $+37^{\circ} \mathrm{C}$.

Serial plasma dilutions were made with phosphate buffered saline, pH 7.4 (PBS) (NPBI, EmmerCompascuum, The Netherlands), and put into polypropylene vessels of $2.2 \mathrm{~mL}$ before (diluted) plasma was transferred into these vessels. Transfer of plasma and diluted plasma was carried out with an automatic pipettor provided with polypropylene tips. The 11 single donor plasmas were prepared from buffycoats which were obtained from the Blood Bank T'wente-Achterhoek [Enschede, The Netherlands]. These buffycoats had been prepared from citrated/ dextran $\Lambda$ blood collected in PVC blood bags. The buffycoats were centrifuged in polypropylene tubes for $15 \mathrm{~min}$ at $1570 \mathrm{~g}$, and the remaining plasmas were centrifuged for $15 \mathrm{~min}$ at $3000 \mathrm{~g}$. The single donor plasmas were put into polypropylene vessels of $2.2 \mathrm{~mL}$ and kept at $-30^{\circ} \mathrm{C}$. For adsorption experiments the same procedures as described for pooled plasma were carried out. Congenitally HMWK-deficient plasma was obtained from George King Biomaterials (Overland Park, KS, (JSA) and kept at $-30^{\circ} \mathrm{C}$. Just hefore use, the plasma was thawed in a water bath of $+37^{\circ} \mathrm{C}$. Purified native (single chain) HMWK (0.6 $\mathrm{mg} \mathrm{m}^{-1}$ ) was kindly provided by Dr B.N. Bouma (Department of Hematology, University Hospital, The Netherlands). The purified HMWK had been characterized extensively ${ }^{20}$. This protein was also kept at $-30^{\circ} \mathrm{C}$ until use.

HMWK-deficient plasma, reconstituted with HMWK, had a HMWK concentration of $70 \mu \mathrm{g} \mathrm{mL}^{-1}$.

\section{Protein adsorption and enzyme-immunoassay}

A description of protein adsorption experiments and the subsequent enzyme-immunoassay (EIA) of adsorbed proteins with the aid of the test device mentioned before has been given by Poot et al. ${ }^{12}$ and Van Damme et al. ${ }^{19}$. A detailed description relevant to our adsorption experiments is given here.

The adsorption experiments as well as the EIA's were carried out at $20^{\circ} \mathrm{C} \pm 1.5^{\circ} \mathrm{C}$. In order to prevent an airplasma-solid interface which might induce protein denaturation, $200 \mu \mathrm{L}$ of PBS was pipetted into the wells of a test device. An adsorption experiment was started by adding $200 \mu \mathrm{L}$ of undiluted or diluted plasma, depending on the experiment, into three wells of a test device. During pipetting of the plasma (solutions), the end of the pipettor tip was kept under the liquid surface but did not touch the test surface. The liquid in the well was gently mixed using the pipettor tip.

$200 \mu \mathrm{L}$ PBS (instead of plasma) was added into two or three wells of each test device. EIA's performed with the contents of these wells served as blanks. When experiments were carried out in which the adsorption time was longer than $\mathbf{5}$ min, the wells of the test device were covered with tape. The wells were also covered after the successive steps of the EIA.

After the desired adsorption time the plasma solutions and the PBS were removed and the wells were rinsed 4 times with $800 \mu \mathrm{L}$ PBS containing $0.005 \%(\mathrm{v} / \mathrm{v})$ Tween-20 (Sigma, St. Louis, USA). This rinsing procedure was also applied after the subsequent steps of the EIA.

The first step of the EIA was started by adding $200 \mu \mathrm{L}$ of the first antibody solution (see below) into the wells. After an exposure time of $1 \mathrm{~h}$ the first antibody solution was removed and the wells were rinsed with PSB-Tween-20; then $200 \mu \mathrm{L}$ of a solution of the enzyme-labelled second antibody (see below) was added. After $1 \mathrm{~h}$ this solution was removed and the wells were rinsed with PBS-Tween-20.

To prevent the detection of protein, which had been adsorbed to the inner walls of the 'Teflon upper part as well as to the Silicone rubber sealing rings of the test device, the polyethylene or the glass plate was mounted into another (cleaned) test device. Hereafter $200 \mu \mathrm{L}$ of a solution of the leuco dye (see below) and the enzyme substrate (hydrogen peroxide; see below) was pipetted into the wells. The enzyme reaction, which was carried out in the dark, was terminated after $30 \mathrm{~min}$ by the addition of $100 \mu \mathrm{L}$ of $2 \mathrm{M}$ sulfuric acid into each well. Part of the dye solution $(250 \mu \mathrm{L})$ was transferred into a well of a 96 wells plate (A/S Nunc, Roskilde, Denmark) and the absorhance was measured at $450 \mathrm{~nm}$ by means of a multiscanner (Reader Micro Elisa System, Organon Teknika, Boxtel, The Netherlands).

The (mean) absorbance value obtained from the blanks was subtracted from the absorbance values determined for protein adsorption experiments. The difference between these values (A450) was used as a measure for the amount of adsorbed protein.

Rabbit serum directed against human fibrinogen (first antibody) was obtained from the Central Laboratory of the Netherlands Red Cross Blood Transfusion Service (CLB) (Amsterdam, The Netherlands). This serum was diluted 100 fold with first antibody buffer. The serum, as well as the other sera and the enzyme-labelled antibodies, were kept at $-30^{\circ} \mathrm{C}$ and thawed in a water bath of $+37^{\circ} \mathrm{C}$ just before use.

The first antibody buffer consists of $8.7 \mathrm{~g} \mathrm{~L}^{-1} \mathrm{NaCl}$, $6.1 \mathrm{gL}^{-1}$ Tris (Merck, Darmstadt, Germany), $0.2 \%$ $(\mathrm{w} / \mathrm{v})$ Tween-20, $0.20 \%(\mathrm{w} / \mathrm{v})$ gelatin (Merck) and $0.5 \%(\mathrm{w} / \mathrm{v})$ bovine serum albumin (BSA, obtained from Sigma) with $\mathrm{pH}$ adjusted to 7.5.

The serum directed against human HDL, i.e. against apoprotein A-1 of HDL, was purchased from Behringwerke AG (Marburg, Germany) and diluted 10 fold with first antibody buffer.

Purified goat antibody $\left(1.8 \mathrm{mg} \mathrm{mL}^{-1}\right)$ directed against the light chain of human HMWK was kindly provided by Dr F. van Iwaarden (Department of Hematology, University Hospital, Utrecht, The Netherlands). This solution was diluted 2000 fold with first antibody buffer.

Sheep anti-rabbit IgG and rabbit anti-goat IgG, both conjugated to horse-radish peroxidase (United States Biochemical Co., Cleveland, USA) were the enzymelabelled antibodies used; these conjugates were diluted 
1:200 000 and 1:6000 respectively in conjugate buffer. When polyethylene was used as a substrate for the adsorption of proteins, the conjugate buffer had the same composition as the first antibody buffer except for a tenfold higher concentration of BSA ( $5 \%)$. When glass is used as a substrate, non-specific adsorption of the enzyme-labelled second antibody may occur. In order to prevent this, BSA in the conjugate buffer was replaced for $10 \%(\mathrm{v} / \mathrm{v})$ of normal sheep serum (CLB). The leuco dye solution consisted of $10 \mathrm{ml}$ of sodium acetate (Janssen, Beerse, Belgium) solution, $0.11 \mathrm{M}$; $\mathrm{pH}=5.5$, and $165 \mu \mathrm{l}$ 3,3,5,5-tetramethyl benzidine (Fluka AG, Buchs, Switzerland) dissolved in DMSO (Merck) $\left(6 \mathrm{mg} \mathrm{mL}^{-1}\right)$. Just before use $10 \mu \mathrm{L}$ of a $3 \%$ peroxide (Merck) solution (with enzyme substrate) were added.

Adsorption experiments and the subsequent EIA's in which the adsorption of fibrinogen from a single donor plasma (or HMWK-reconstituted plasma) was compared with fibrinogen adsorption from pooled plasma, were carried out simultaneously.

Seven couples of experiments in which fibrinogen adsorption from single donor plasmas (Figure 1) and fibrinogen adsorption from pooled plasma were determined, were carried out in $7 \mathrm{~d}$. Four other couples of experiments were performed in $2 \mathrm{~d}$ (each day two samples).

In experiments in which glass or polyethylene (mounted in a test device) were pre-exposed to plasma solutions and subsequently exposed to $1: 1$ diluted plasma, the pre-exposed surfaces were rinsed four times with $800 \mu \mathrm{l}$ PBS containing $0.005 \%(\mathrm{v} / \mathrm{v})$ Tween20. After rinsing, $200 \mu \mathrm{L}$ of PBS was pipetted into the wells. Thereafter $200 \mu \mathrm{L}$ of undiluted plasma was pipetted into these wells. The same precautions for the pipetting of plasma solutions into the wells were taken as described above.

\section{RESULTS}

The adsorption of fibrinogen to glass from a single donor plasma (donor 6) and from pooled normal human plasma as a function of time are shown in Figure 2. Both fibrinogen adsorption curves show a strong decrease during the first $10 \mathrm{~min}$ of adsorption and reach a plateau level after about $10 \mathrm{~min}$.

The fibrinogen adsorption curves determined for the other 10 donor plasmas and the corresponding curves for pooled plasma have a similar shape as the curves of Figure 2. A two way analysis of variance (two plasmas and different adsorption times) revealed that the values for fibrinogen adsorption from the single donor plasma (donor 6), measured after $1 \mathrm{~min}, 5 \mathrm{~min}$, $10 \mathrm{~min}$ and $60 \mathrm{~min}$, respectively, are not significantly different compared with the corresponding values for fibrinogen adsorption from pooled plasma, i.e. the curve representing fibrinogen adsorption from the single donor plasma as a function of time does not differ significantly from the curve obtained for pooled plasma. Small but significant differences were found between the fibrinogen adsorption curves determined for 7 of the other 10 single donor plasmas and the corresponding curves for pooled plasma. Larger

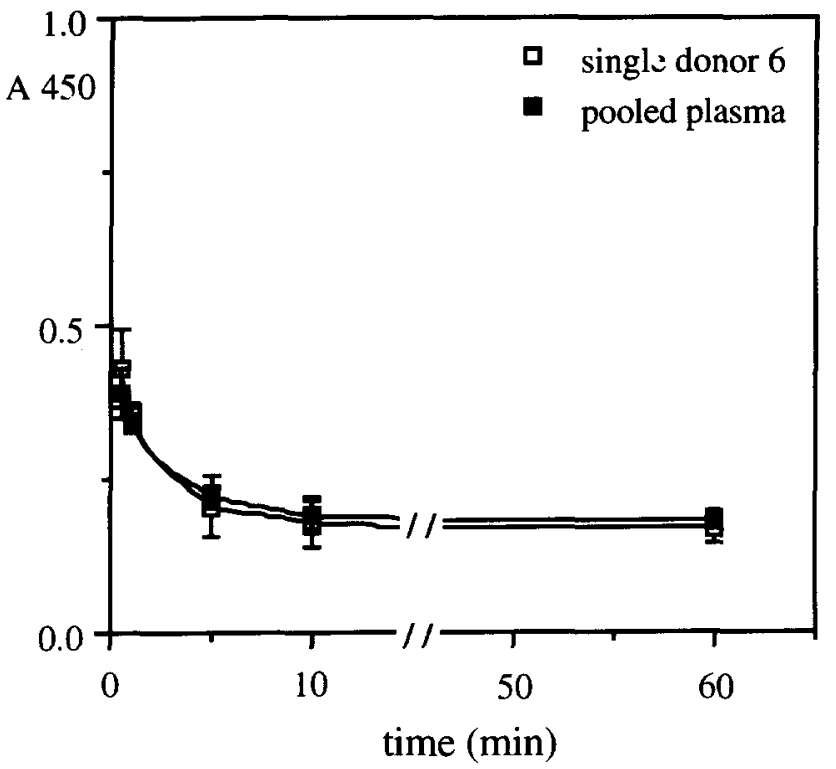

Figure 1 Adsorption of fibrinogen to glass from 1:1 diluted human plasmas as a function of time. $\square$ a single donor plasma, pooled plasma. Adsorption values (A450) with regard to the two adsorption curves were determined simultaneously in threefold $( \pm S D)$. Temperature $20^{\circ} \mathrm{C}$.

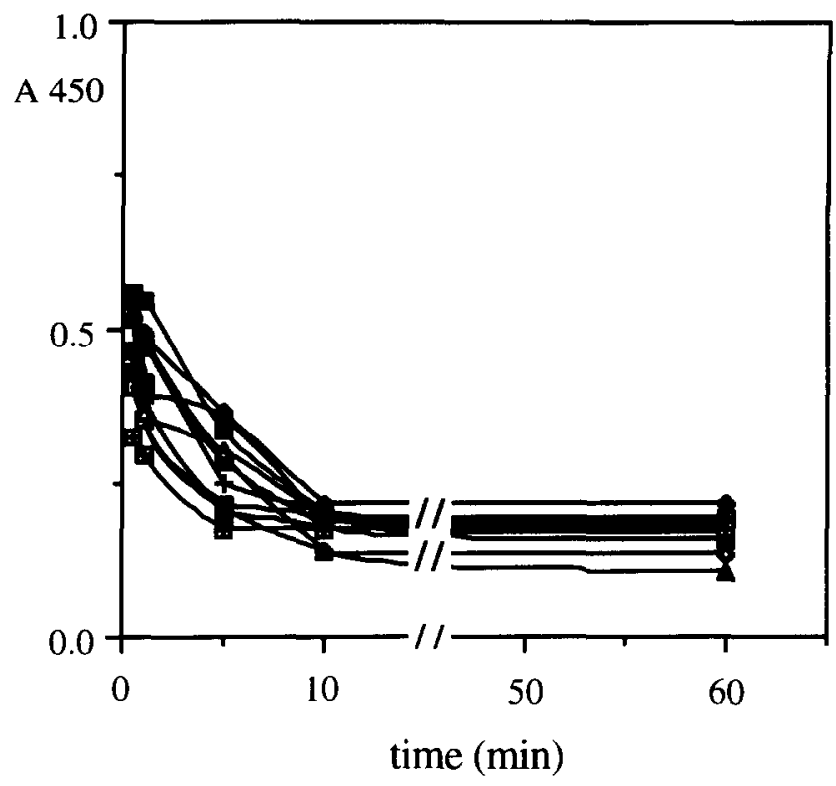

Figure 2 Adsorption (A450) of fibrinogen to glass from 11 donor plasmas (1:1 diluted) as a function of time. Most of the single donor curves were determined at different days (see Materials and methods section). Temperature $20^{\circ} \mathrm{C}$.

differences were observed between the fibrinogen adsorption curves for the 11 donor plasmas (Figure 2). This was also the case for the differences between the 11 fibrinogen adsorption curves obtained with pooled plasma (not shown). The mean values \pm standard deviations for the adsorption of fibrinogen to glass from single donor plasmas as well as from pooled plasma after the various plasma-incubation times are shown in Figure 3. The two adsorption curves belonging to these values are also given in this figure. To calculate standard deviations, the number of 


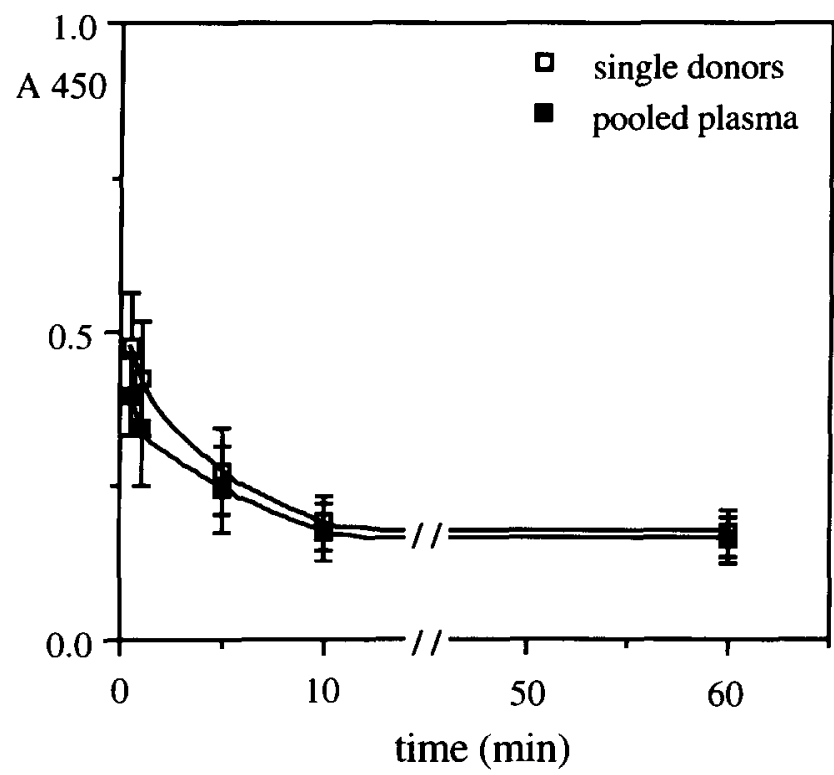

Figure 3 Mean adsorption curves for the adsorption of fibrinogen to glass from 11 single donor plasmas (1:1 diluted) and pooled plasma (1:1 diluted) as a function of time $(n=33 \pm \mathrm{SD})$. Temperature $20^{\circ} \mathrm{C}$.

experiments (n) with respect to each incubation time was 33 in the case of pooled plasma. In the case of single donor plasmas $n$ was also 33 . A small but significant difference was found between the two adsorption curves of Figure 3 . No significant difference between the plateau values of the curves was found.

In Figure 4 the fibrinogen adsorption from three different kinds of plasma to glass as a function of time is presented. The three plasmas were: pooled normal human plasma, HMWK-deficient plasma, and HMWKdeficient plasma which had been reconstituted with HMWK.

The A450 value (the absorbance at $450 \mathrm{~nm}$ of the dye solution, formed in the enzyme-immunoassay) for the amount of HMWK adsorbed from 1:1 diluted HMWK-deficient plasma was found to be $0.12 \pm 0.046$ (result not shown). In the case of 1:1 diluted normal plasma the A450 value for the amount of adsorbed HMWK is about 0.80 (Figure 5). The fibrinogen adsorption curve for HMWK-deficient plasma (Figure 4 ) is located at a significantly higher level than the curve for pooled plasma, especially for adsorption times larger than $5 \mathrm{~min}$. For adsorption times larger than $1 \mathrm{~min}$ the HMWK-deficient plasma curve is also located at a higher level than the fibrinogen adsorption curves obtained from experiments with the single donor plasmas (Figure 2). The values for fibrinogen adsorption from HMWK-deficient plasma, reconstituted with HMWK, are significantly lower than the corresponding values for HMWK-deficient plasma $(p=0.012)$. This is demonstrated by the middle curve of Figure 4 . The plateau level of the fibrinogen adsorption curve for the reconstituted plasma is not significantly different compared with the plateau level of the upper single donor curve presented in Figure 2. It must be mentioned, however, that the single donor curves are the result of experiments, which were not carried out

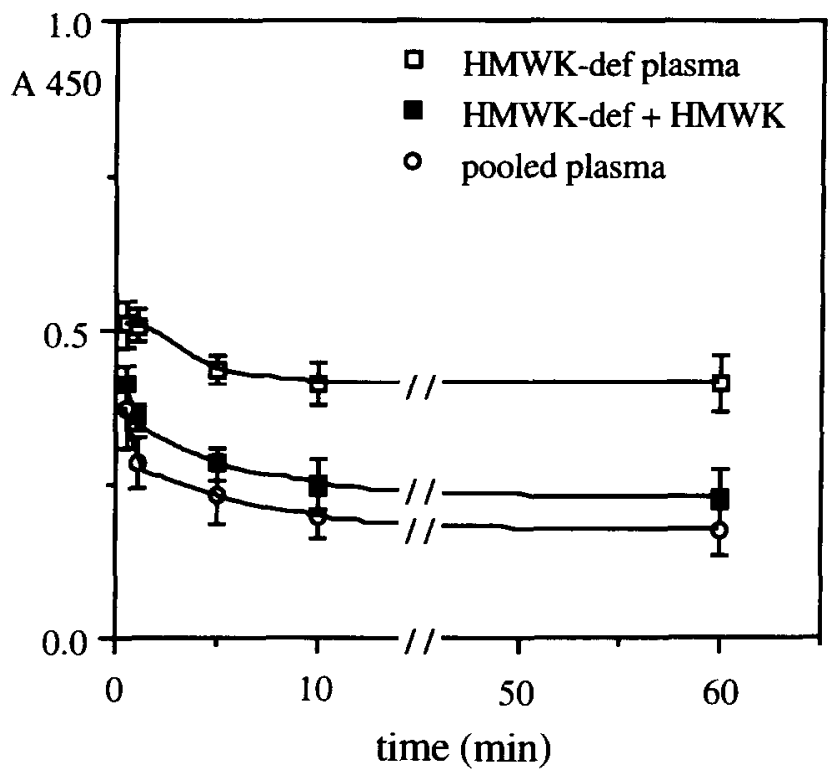

Figure 4 Adsorption of fibrinogen to glass from 1:1 diluted human plasmas as a function of time. $\square$ single donor high molecular weight kininogen (HMWK)-deficient plasma, HMWK-deficient plasma, reconstituted with HMWK $\left(70 \mu \mathrm{g} \mathrm{mL}^{-1}\right), O$ pooled plasma. Adsorption values (A450) with regard to the three adsorption curves were determined simultaneously in threefold $( \pm \mathrm{SD})$. Temperature $20^{\circ} \mathrm{C}$.

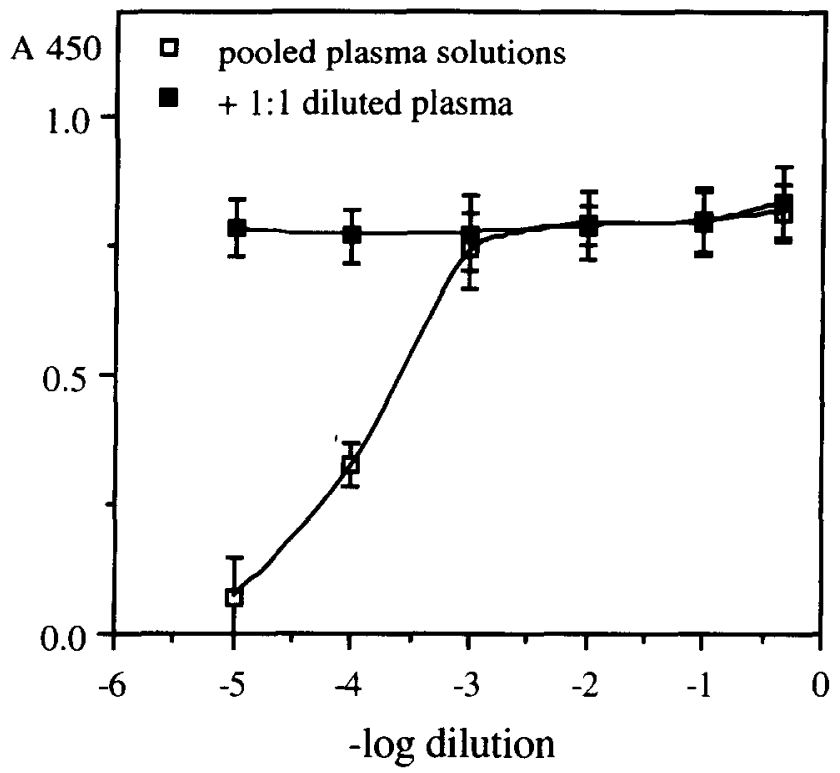

Figure 5 Adsorption of HMWK to glass as a function of the plasma concentration ( $\square$ ). Adsorption time $1 \mathrm{~h}$. Pooled human plasma was used to make plasma dilutions of $1: 100000,1: 10000,1: 1000,1: 100,1: 10$ and 1:1. In a simultaneous experiment glass surfaces were first pre-exposed for $1 \mathrm{~h}$ to plasma solutions with the same plasma dilutions. The pre-exposed glass surfaces were subsequently exposed to $1: 1$ diluted pooled plasma for $1 \mathrm{~h}$ and the amounts of adsorbed HMWK ( $\square$ ) were determined. Adsorption values (A450) were determined in threefold $( \pm S D)$. Temperature $20^{\circ} \mathrm{C}$.

simultaneously with the experiments from which the results are presented in Figure 4.

In Figure 5 the adsorption of HMWK from plasma 
solutions to glass as a function of the plasma concentration is presented $(\square)$. The adsorption time was $1 \mathrm{~h}$, and six plasma dilutions were taken: 1:100 000, 1:10000, 1:1000, 1:10 and 1:1. In a simultaneous experiment glass surfaces were exposed to solutions with the same plasma concentrations. After $1 \mathrm{~h}$ these 'precoated' glass surfaces were exposed to $1: 1$ diluted plasma for $1 \mathrm{~h}$. Thereafter the amounts of HMWK adsorbed to the precoated glass surfaces were determined ( $\square$ ).

The amounts of HMWK adsorbed from very diluted plasma solutions to uncoated glass increase with increasing plasma concentration. Above a plasma concentration of about $0.1 \%$ the adsorption of HMWK to glass reaches a plateau value.

Glass pre-exposed to a plasma solution for $1 \mathrm{~h}$ and subsequently exposed to $1: 1$ diluted plasma for $1 \mathrm{~h}$, gives rise to an adsorption of HMWK which is independent of the plasma concentration of the precoating solution. This amount of HMWK is not significantly different compared with the adsorbed amount of HMWK which corresponds to the above mentioned plateau value.

The A450 values for the amounts of albumin and fibrinogen adsorbed to glass from 1:1000 diluted plasma are given in Figure 6. After a subsequent exposure of the pre-exposed glass surface to 1:1 diluted plasma the A450 values for the amounts of adsorbed albumin and fibrinogen were found to be about $50 \%$ of the former values. The A450 value for the amount of adsorbed HMWK did not change significantly after the subsequent exposure to $1: 1$ diluted plasma.

Similar experiments as described above were carried out with polyethylene as a solid substrate, but in these experiments the amounts of adsorbed HDL

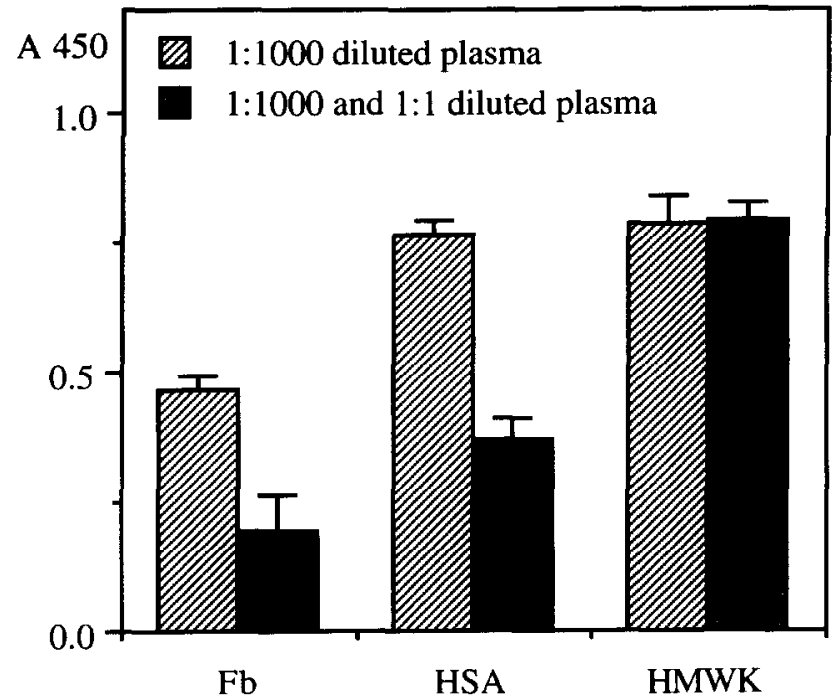

Figure 6 Adsorption of fibrinogen (Fb), albumin (HSA) and HMWK to glass from 1:1000 diluted pooled plasma ( $\square$ ). Adsorption time $1 \mathrm{~h}$. In a simultaneous experiment glass surfaces were first pre-exposed to $1: 1000$ diluted pooled plasma for $1 \mathrm{~h}$ and subsequently exposed to $1: 1$ diluted pooled plasma for $1 \mathrm{~h}$. Thereafter the adsorbed amounts of fibrinogen, albumin and HMWK were determined ( $\square$ ). Adsorption values (A450) were determined in threefold $\left( \pm\right.$ SD). Temperature $20^{\circ} \mathrm{C}$.

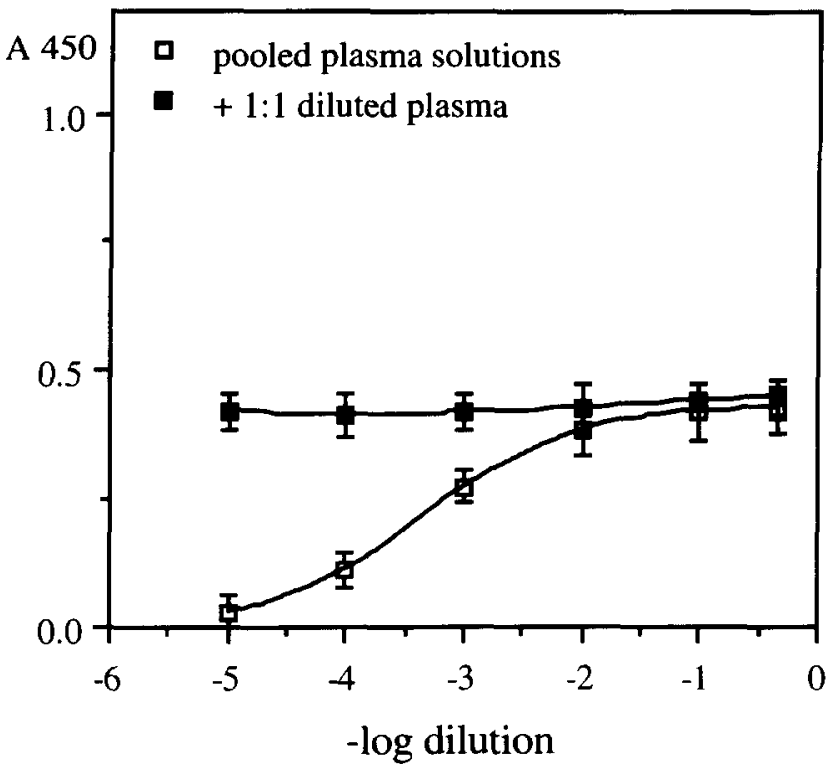

Figure 7 Adsorption of HDL to polyethylene as a function of the plasma concentration ( $\square$ ). Adsorption time $1 \mathrm{~h}$. Pooled human plasma was used to make plasma dilutions of $1: 100000,1: 10000,1: 1000,1: 100,1: 10$ and 1:1. In a simultaneous experiment polyethylene surfaces were first pre-exposed for $1 \mathrm{~h}$ to plasma solutions with the same plasma dilutions. The pre-exposed polyethylene surfaces were subsequently exposed to $1: 1$ diluted pooled plasma for $1 \mathrm{~h}$ and the amounts of adsorbed HDL ( $\boldsymbol{C})$ were determined. Adsorption values (A450) were determined in threefold $( \pm S D)$. Temperature $20^{\circ} \mathrm{C}$.

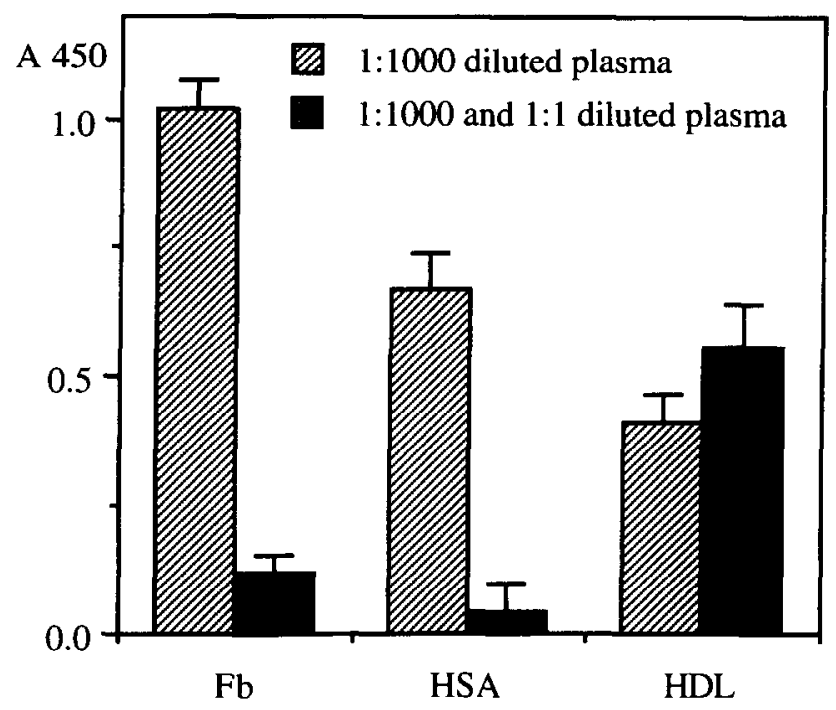

Figure 8 Adsorption of fibrinogen ( $\mathrm{Fb}$ ), albumin (HSA) and HDL to polyethylene from 1:1000 diluted pooled plasma (D). Adsorption time $1 \mathrm{~h}$. In a simultaneous experiment glass surfaces were first pre-exposed to 1:1000 diluted pooled plasma for $1 \mathrm{~h}$ and subsequently exposed to 1:1 diluted pooled plasma for $1 \mathrm{~h}$. Thereafter the adsorbed amounts of fibrinogen, albumin and HDL were determined (ロ). Adsorption values (A450) were determined in threefold ( \pm SD). Temperature $20^{\circ} \mathrm{C}$.

instead of HMWK were determined. The results of the adsorption experiments are presented in Figure 7. Adsorption times taken as $1 \mathrm{~h}$. The amounts of HDL adsorbed from very diluted plasma solutions to 
uncoated polyethylene increase with increasing plasma concentration ( $\square$ ). Above a plasma concentration of about $1 \%$ the amount of HDL adsorbed to polyethylene reaches a plateau value. Polyethylene pre-exposed to a plasma solution for $1 \mathrm{~h}$ and subsequently exposed to $1: 1$ diluted plasma for $1 \mathrm{~h}$ gives rise to an adsorption of HDL, which is independent of the plasma concentration of the precoating solution (a). This amount of HDL is (practically) the same as the amount of adsorbed HDL which corresponds to the above-mentioned plateau value.

The A450 values for the amounts of albumin and fibrinogen adsorbed to polyethylene from 1:1000 diluted plasma are given in Figure 8 . After a subsequent exposure of the pre-exposed polyethylene surface to $1: 1$ diluted plasma the A450 values for the amounts of adsorbed albumin and fibrinogen were found to be less than $25 \%$ of the former values.

The A450 value for the amount of adsorbed HDL hardly increased after the subsequent exposure to $1: 1$ diluted plasma.

\section{DISCUSSION}

Several studies strongly suggest that fibrinogen, initially adsorbed from blood plasma to glass or a glass-like surface, is subsequently displaced from the surface by HMWK. These studies include experiments in which the time dependent adsorption of fibrinogen from single donor HMWK-deficient plasma has been compared with the adsorption of fibrinogen from normal single donor plasma or from pooled human plasma. The amount of adsorbed fibrinogen may, however, depend on the plasma composition, notably the concentration of fibrinogen itself ${ }^{16}$. In order to get more insight into the real differences between normal donor plasmas and HMWK-deficient plasma with respect to fibrinogen adsorption, we determined the adsorption of fibrinogen to glass from 11 normal donor plasmas and pooled plasma as a function of time. The 11 donors did not belong to the group of 15 donors, who donated blood for the preparation of pooled plasma. Protein adsorption was measured with a twostep enzyme-immunoassay (EIA). The EIA experiments do not yield quantitative amounts of adsorbed protein. Above a certain surface concentration of an adsorbed protein steric hindrance between the first antibody molecules on the surface may occur. Moreover, protein molecules may undergo conformational changes during and after adsorption. As a consequence, several antigenic determinants of an adsorbed protein molecule may lose their specific structure and are not able to react with antigen binding sites of the applied antibody. This phenomenon not only depends on the properties of the protein and the material surface, but also on the possibility of the protein to unfold and spread upon the surface which is time-dependent and influenced by the surface concentrations of proteins already adsorbed. Therefore a comparison of the EIA data with those of a quantitative method like radiolabeling is very difficult ${ }^{19}$.

To prevent an air-plasma-solid interface which might induce protein denaturation, buffer was brought into the wells of an EIA test device before plasma was added (see Materials and methods section). For this reason the time dependent adsorption of fibrinogen from 1:1 diluted plasma instead of undiluted plasma was determined. The curves representing fibrinogen adsorption to glass as a function of time show for the single donor plasmas as well as pooled plasma a strong decrease during the first $10 \mathrm{~min}$ and reach low plateau values after that time. This phenomenon has also been found by Brash et al. ${ }^{10}$ and Poot et al. ${ }^{12}$. In the study of Poot et al. ${ }^{12}$ 1:1 diluted plasma was used, while Brash el $u l^{10}$ used plasma diluted to 2.5 and $0.5 \%$. In the latter case, however, the amount of fibrinogen adsorbed to glass still decreased after $3 \mathrm{~h}$, probably because an equilibrium between fibrinogen in solution and adsorbed fibrinogen had not yet been reached. Fibrinogen adsorption curves determined for 7 of the 11 donor plasmas showed a small but significant difference compared with the corresponding curves for pooled plasma. This is not surprising because it is well known that the protein composition of human plasmas varies ${ }^{21}$ and as a result the adsorbed amounts of a particular protein may be different. The real differences between the single donor curves are most probably smaller than the differences represented in Figure 2, because the results of EIA experiments show a day-to-day fluctuation ${ }^{19}$.

The two mean fibrinogen adsorption curves for single donor plasmas and pooled plasma, presented in Figure 3 show a very small difference if a two-way analysis of variance is applied. This difference appears during the first $10 \mathrm{~min}$ of adsorption because no significant difference between the plateau values of the curves is found. The reason for this difference between the decreasing parts of the adsorption curves is not known.

The A450 value of 0.12 , corresponding with the amount of HMWK adsorbed from 1:1 diluted HMWKdeficient plasma to glass, is small compared with the A450 value of about 0.80 in the case of a normal plasma. Therefore it may be concluded that the deficient plasma contained only a small amount of HMWK.

The fibrinogen adsorption curve for HMWK-deficient plasma (Figure 4) is located at a much higher level than the curve for pooled plasma. Moreover, for adsorption times larger than $1 \mathrm{~min}$, the curve for the deficient plasma is also located at a significantly higher level than the adsorption curves oblained with the 11 single donor plasmas. These findings strongly suggest that at all events plateau values of fibrinogen adsorption curves obtained with normal donor plasmas will always be located at a significantly lower level than a fibrinogen adsorption plateau obtained with a single donor HMWK-deficient plasma. The fibrinogen adsorption curve obtained with the HMWK-deficient plasma, reconstituted with HMWK to a physiological level of $70 \mu \mathrm{g} \mathrm{mL}^{-1}$, is located at a somewhat higher level than the curve for pooled plasma. The plateau level of the former curve is, however, not significantly different compared to the plateau level of the upper single donor curve presented in Figure 2. This means that addition of HMWK to HMWK-deficient plasma is 
responsible for the fact that fibrinogen adsorption from the reconstituted plasma to glass is about the same as fibrinogen adsorption from a normal plasma. This result supports the conclusion of several authors ${ }^{7-12}$, including ourselves, that HMWK is involved in the displacement of fibrinogen, initially adsorbed from normal plasma to glass. The decrease of fibrinogen adsorption from HMWK-deficient plasma during the first $10 \mathrm{~min}$ of exposure to glass indicates, however, that one or more other proteins are also involved in the displacement of adsorbed fibrinogen.

At low plasma concentrations the amount of HMWK, adsorbed to glass, increases with increasing plasma concentration (Figure 5). Above a plasma concentration of about $\mathbf{0 . 1 \%}$ a plateau value for the amount of adsorbed HMWK is reached. These results are in agreement with those of earlier experiments ${ }^{12}$. The concentration of HMWK in very diluted normal plasma is apparently decreased below such a low value that other proteins, which are rapidly adsorbed, cannot be replaced any more by HMWK. At relatively high plasma concentrations relatively small amounts of other plasma proteins like albumin, immunoglobulin G, fibrinogen, fibronectin and Factor VIII adsorb to glass ${ }^{12}$. The high HMWK adsorption plateau, which is reached when glass is exposed to a solution with a plasma concentration higher than about $0.1 \%$, indicates that HMWK preferentially adsorbs onto glass and may displace initially adsorbed plasma proteins from the glass surface.

The displacement of adsorbed plasma proteins was also studied in another way. Glass surfaces were first pre-exposed to solutions with different concentrations of plasma, resulting in protein layers with different protein compositions. The precoated glass surfaces were subsequently exposed to $1: 1$ diluted plasma. Thereafter the amounts of HMWK in the newly formed protein layers were compared with the amounts of this protein present on the pre-exposed glass surfaces. Earlier experiments ${ }^{12}$ demonstrated that glass surfaces, which were exposed to $1: 100000$ to 1:1000 diluted plasma, i.e. precoated surfaces to which smaller amounts of HMWK had been adsorbed compared to the amount of HMWK represented by the abovementioned adsorption plateau, had adsorbed relatively large amounts of proteins like albumin, immunoglobulin G, fibrinogen, fibronectin, Factor VIII and most probably many other proteins. All the pre-exposed glass surfaces, which were subsequently exposed to 1:1 diluted plasma, give rise to the same amount of adsorbed HMWK which is equal to the amount of HMWK represented by the HMWK adsorption plateau, mentioned earlier. This indicates that HMWK, adsorbing from the 1:1 diluted plasma, is involved in the displacement of proteins from glass surfaces which had been pre-exposed to solutions with a plasma concentration below $0.1 \%$.

From Figure 6 it may be concluded that about $50 \%$ of the amounts of albumin and fibrinogen, adsorbed to glass from 1:1000 diluted plasma, are displaced from the glass surface by one or more other plasma proteins after a subsequent exposure of the surface to $1: 1$ diluted plasma. In this case HMWK is not responsible for the displacement of albumin and fibrinogen, because the amount of adsorbed HMWK did not significantly change after the subsequent exposure to 1:1 diluted plasma. This conclusion may also be drawn from Figure 5, which shows that the amount of HMWK, adsorbed to glass from 1:1000 diluted plasma, already reaches the HMWK plateau value.

To investigate the displacement of proteins, adsorbed to polyethylene from plasma solutions, similar experiments were carried out as discussed above, but in those experiments the adsorbed amounts of HDL instead of HMWK were determined. The amount of HDL adsorbed to polyethylene increases as a function of the plasma concentration and reaches a plateau value at a plasma concentration of about $1 \%$ (Figure 7). This result agrees well with the result of experiments reported earlier ${ }^{22}$. A similar result was found for the adsorption of HDL from plasma solutions to $\mathrm{PVC}^{13}$

The relatively low adsorption plateau of HDL may be owing to the fact that only parts of the HDL molecule consists of apoprotein A-1 against which the first antibody is directed. This results in a relatively low surface concentration of antibody molecules, which in turn leads to a low A450 value ${ }^{19}$.

Earlier experiments revealed that polyethylene which had been exposed to $1: 100000$ to $1: 100$ diluted plasma, i.e. precoated polyethylene surfaces to which smaller amounts of HDL had been adsorbed compared to the amount corresponding with the HDL adsorption plateau, had adsorbed relatively large amounts of other proteins such as albumin, immunoglobulin G, fibrinogen, fibronectin and $\mathrm{HMWK}^{12}$. In the present experiments in which polyethylene surfaces were exposed to solutions with very different plasma concentrations and subsequently exposed to 1:1 diluted plasma, the same amounts of adsorbed HDL were found. These amounts are equal or practically equal to the amount corresponding with the HDL adsorption plateau mentioned above. A similar result was obtained in earlier experiments ${ }^{22}$. These results reveal that HDL, adsorbing from the 1:1 diluted plasma, is involved in the displacement of proteins from polyethylene surfaces, which had been pre-exposed to solutions with a plasma concentration below 1\%. From Figure 8 it may be concluded that the major part of albumin and fibrinogen, adsorbed to polyethylene from 1:1000 diluted plasma, is displaced from the polyethylene surface by one or more other plasma proteins after a subsequent exposure of the surface to $1: 1$ diluted plasma. Figure 8 also shows that there is only a small increase in the amount of adsorbed HDL after exposure of the precoated polyethylene surface to 1:1 diluted plasma. This indicates that one or more proteins different from HDL is (are) involved in the displacement of adsorbed albumin and fibrinogen from the polyethylene surface which had been preexposed to 1:1000 diluted plasma.

In the foregoing text the displacement of preadsorbed proteins by proteins from 1:1 diluted plasma was discussed. However, similar displacement phenomena will occur when a material surface is exposed directly to plasma or a plasma solution, because it probably makes little difference whether a 
certain surface concentration of a particular protein has been obtained by 'precoating' or by a direct exposure to plasma during a definite time. The results obtained thus far indicate that many proteins are involved in the Vroman effect during exposure of a material surface to plasma.

\section{REFERENCES}

1 Poot A, Beugeling T, Cazenave JP, Bantjes A, Van Aken WG. Platelet deposition in a capillary perfusion model: Quantitative and morphological aspects. Biomaterials 1988; 9: 126-132.

2 Lambrecht LK, Young BR, Stafford RE, Park K, Albrecht RM, Mosher DF, Cooper SL. The influence of preadsorbed canine von Willebrand factor, fibronectin and fibrinogen on ex vivo artificial surface-induced thrombosis. Thromb Res 1986; 41: 99-117.

3 Lee RG, Kim SW. Adsorbed glycoproteins in platelet adhesion onto polymer surfaces: significance of terminal galactose units. Trans Am Soc Artif Intern Organs 1979; 25: 124-131.

4 Poot A. Protein adsorption and platelet deposition on biomaterials: in vitro studies concerning blood compatibility. PhD Thesis 1988. University of Twente, Enschede, The Netherlands.

5 Kaplan AP, Silverberg M. The coagulation-kinin pathway of human plasma. Blood 1987; 70: 1-15.

6 Vroman L, Adams AL. Identification of rapid changes at plasma-solid interfaces. J Biomed Mater Res 1969; J: 43-67.

7 Vroman L, Adams AL, Fisher GC, Munoz PC. Interaction of high molecular weight kininogen, Factor XII and fibrinogen in plasma at interfaces. Blood 1980; 55: 156-159.

8 Schmaier AH, Silver L, Adams AL, Fisher GC, Munoz PC, Vroman L, Colman RW. The effect of high molecular weight kininogen on surface-adsorbed fibrinogen. Thromb Res 1983; 33: 51-67.

9 Brash JL, Ten Hove P. Effect of plasma dilution on adsorption of fibrinogen to solid surfaces. Thromb Haemostas 1984; 51: 326-330.

10 Brash JL, Scott CF, Ten Hove P, Wojciechowski P, Colman RW. Mechanism of transient adsorption of fibrinogen from plasma to solid surfaces: Role of the contact and fibrinolytic systems. Blood 1988; 71: 932-939.

11 Elwing $\mathrm{H}$, Askendal A, Lundström I. Competition between adsorbed fibrinogen and high molecular weight kininogen on solid surfaces incubated in human plasma (the Vroman effect): influence of solid surface wettability. $J$ Biomed Mater Res 1987; 21: 1023-1028.

12 Poot A, Beugeling T, Van Aken WG, Bantjes A. Detection of surface-adsorbed (lipo)proteins by means of a two-step enzyme-immunoassay: A study on the Vroman effect. $J$ Biomed Mater Res 1990; 24: 1021-1036.

13 Breemhaar W, Brinkman E, Ellens DJ, Beugeling T, Bantjes A. Preferential adsorption of high density lipoprotein from blood plasma onto biomaterial surfaces. Biomaterials 1984; 5: 269-274.

14 Horbett TA. Mass action effects on competitive adsorption from hemoglobin solutions and from plasma. Thromb Haemostas 1984; 51: 174-181.

15 Brash JL. In: Missirlis YF, Lemm W, eds. Modern aspects of protein adsorption on biomaterials. Dordrecht, The Netherlands: Kluwer, 1991: 201.

16 Slack SM, Horbett TA. Physico-chemical and biomedical aspects of fibrinogen adsorption from plasma and binary protein solutions onto polyethylene and glass. $J$ Colloid Interface Sci 1988; 124: 535-551.

17 Brash JL, Uniyal S, Chan BMC. Interactions of protein in plasma with various foreign surfaces. Artif Organs 1981; 5 (suppl.): 475-477.

18 Uniyal S, Brash JL. Patterns of adsorption of proteins from human plasma onto foreign surfaces. Thromb Haemostas 1982; 47: 285-290.

19 Van Damme HS, Beugeling T, Ratering MT, Feijen J. Protein adsorption from plasma onto poly(n-alkyl methacrylate) surfaces. I Biomater Sci Polymer Edn 1991; 3: 69-84.

20 Van Iwaarden F, De Groot PhG, Sixma JJ, Berrettini M, Bouma BN. High molecular weight kininogen is present in cultured human endothelial cells: localization, isolation and characterization. Blood 1988; 71: 1268.

21 Ritchi RF. In: Putman FW, ed. The plasma proteins. New York: Academic Press, 1975: 418.

22 Beugeling T. In: Missirlis YF, Lemm W, eds. Modern Aspects of protein adsorption on biomaterials. Dordrecht, The Netherlands: Kluwer, 1991: 211-212. 